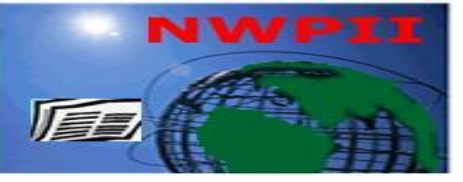

American Journal of Biomedical Sciences

ISSN: 1937-9080

nwpii.com/ajbms

\title{
Immunogenicity of Nitric Oxide Modified Chromatin and Its Implications in Systemic Lupus Erythematosus
}

\author{
Sarah Afaq $^{1 *}$ and Rashid Ali ${ }^{2}$ \\ ${ }^{1}$ Department of Clinical Biochemistry, College of Medicine, King Khalid University, Abha, Kingdom of \\ Saudi Arabia \\ ${ }^{2}$ Department of Biochemistry, College of Medicine, Jawahar Lal Nehru Medical College, Aligarh, India \\ *Corresponding author \\ Sarah Afaq,PhD \\ Assistant Professor \\ Department of Clinical Biochemistry \\ College of Medicine \\ King Khalid University, Abha \\ Kingdom of Saudi Arabia \\ PO Box 641 \\ Email: sarah.afaq@gmail.com
}

Received: 28 June 2009; | Revised: 16 August 2009; | Accepted: 15 December 2009

\begin{abstract}
Freshly isolated chromatin from goat liver, exposed to nitric oxide (generated by the reduction of sodium nitrite with sodium dithionite) caused structural alterations and loss of tertiary structure of chromatin along with strand breaks and base modifications in the DNA of chromatin. The NO-chromatin was highly immunogenic in experimental animals as compared to its native form. Induced antibodies were highly specific for their respective immunogen. However, delineating the antigenic specificity of anti -NOchromatin antibodies by competition ELISA, multiple cross-reactivity was observed. Anti-NO-chromatin antibodies recognized human blood proteins, modified tyrosine polymers and histones. Moreover, NO modified conformers were better recognized than their native forms. The visual detection of immune complex formation with native and NO-chromatin reiterated preferential binding with modified chromatin. Chromatin modified by nitric oxide presents unique epitopes which may be one of the factors in antigen driven autoimmune response in SLE.
\end{abstract}

Keywords: autoantibodies; chromatin; NO-chromatin; nitric oxide; SLE.

\section{Introduction}

Nitric oxide (NO), a multifaceted bioregulatory agent (vasodilator, neurotransmitter) produced by many cell types is known to play a critical role in both regulatory processes and cell defense. It also participates in collateral reactions, leading to DNA damage and cell death in both

(C) 2010 by NWPII. All rights reserved. 
NO-generating and neighboring cells [1]. It can accelerate DNA base deamination, strand breaks and cause deamination-induced genetic changes in lung cells [2]. Besides these effects, NO also causes tissue injury by attacking the Fe-S centers in various key proteins [3], inhibiting ribonucleotide reductase [4] and several other DNA repair/replication enzymes $[5,6]$.

SLE is an autoimmune disorder of unknown etiology. Antibodies to dsDNA is a classic antibody that characterizes SLE[7]. However, the dominant presence of antibodies against the exposed conformational epitopes on chromatin strongly suggests that the pathogenic immune response in lupus is driven by chromatin $[8,9,10,11,12,13]$. The nucleosomes(or chromatin)is emerging as the most reactive substrate among nuclear antigens, $70 \%-80 \%$ of SLE patients being positive. Also, anti-chromatin (or nucleosomes) antibodies might be a good marker for anti-DNA antibodies negative SLE cases [14].

Nitric oxide is generated in vivo by many types of cells through the nitric oxide synthase(NOS) pathway[15,16]. It is an important mediator of the inflammatory response. Activated macrophages produce nitric oxide which damages DNA resulting in mutations and strand breaks[1]. Retrospective studies have suggested a role of nitric oxide in the pathogenesis of SLE by demonstrating elevated levels of nitric oxide in these patients[17,18].In the present study, we have investigated immunogenicity of native chromatin and nitric oxide modified chromatin(NOchromatin). The notable feature of this investigation is the high degree of recognition of nitric oxide modified conformers of histones, nucleosomes and human blood protein by antiNO-chromatin antibodies.

\section{Materials and methods}

\subsection{Materials}

Sodium nitrite and sodium dithionite were purchased from Bio-Rad laboratories (California, USA). Calf thymus DNA, nuclease S1,methylated bovine serum albumin(BSA), anti-rabbit IgG alkaline phosphatase conjugate,Freund's complete and incomplete adjuvants, ethidium bromide,
Ficoll-400,bromophenol blue p-nitrophenyl phosphate, Tween-20, Triton X-100 were procured from Sigma-Aldrich (St.Louis, MO, USA). Protein A-Sepharose CL-4b was purchased from Genei (India). Polystyrene microtitre flat bottom ELISA plates were procured from NUNC (Denmark).Agarose was purchased from Pharmacia (Sweden). All other chemicals were of analytical grade.

\subsection{Methods}

\subsubsection{Isolation of chromatin}

Chromatin was isolated from fresh goat liver by the method of Bonner et al [19] with slight modifications. Briefly, $10 \mathrm{~g}$ of goat liver was homogenized with $200 \mathrm{ml}$ of saline-EDTA $(0.075 \mathrm{M} \mathrm{NaCl}$, and $0.024 \mathrm{M}$ EDTA, $\mathrm{pH} 8.0)$. The homogenate was strained through 6-8 layer of cheese cloth. The filtrate was centrifuged at $1500 \mathrm{~g}$ for $15 \mathrm{~min}$. the pellet was homogenized in $40 \mathrm{ml}$ of Tris buffer $(0.05 \mathrm{M}, \mathrm{pH} 8.0)$ and sedimented at $10,000 \mathrm{~g}$ for $15 \mathrm{~min}$. This step was repeated once. The final pellet was suspended in $30 \mathrm{ml}$ of Tris buffer (0.05 M, pH 8.0). Five milliliter aliquots of the above suspension were layered on $25 \mathrm{ml}$ portions of $1.7 \mathrm{M}$ sucrose (in $0.01 \mathrm{M}$ Tris buffer, $\mathrm{pH}$ 8.0) contained in centrifuge tubes. The upper two thirds of each tube were gently mixed and the tubes were then centrifuged at 21,000 rpm for $3 \mathrm{~h}$ in $\mathrm{F} 0650$ rotor (Beckman) at $4^{\circ} \mathrm{C}$. The pellets were suspended in $0.01 \mathrm{M}$ Tris buffer, pH8.0, and dialyzed overnight against the same buffer. The dialyzed suspension was sheared in Viritis homogenizer for $90 \mathrm{~s}$, stirred for $30 \mathrm{~min}$ and then centrifuged at $10,000 \mathrm{~g}$ for $30 \mathrm{~min}$. The supernatant of the above is referred to as sheared liver chromatin.

\subsubsection{Modification of chromatin by nitric oxide}

Isolated chromatin was modified with nitric oxide generated by the reduction of sodium nitrite with sodium dithionite $[20,21]$. Aqueous solution of chromatin in PBS (A260=2), $20 \mathrm{mM}$ Tris- $\mathrm{HCl}$ buffer, $\mathrm{pH} 7.5$, sodium nitrite $(100 \mathrm{mM})$ and sodium dithionite $(10 \mathrm{mM})$ was kept at $37^{\circ} \mathrm{C}$ for 3 h. Extensive dialysis of the sample was done immediately at the end of incubation time to remove the salts. Native chromatin incubated with 
salts alone served as control. The UV absorption characteristics of native and NO-chromatin were recorded on a Shimadzu UV-240 spectrophotometer. All the other samples like nucleosomes, histones, tyrosine polymers and human serum albumin were similarly modified.

\subsubsection{Agarose gel electrophoresis}

Native and NO-chromatin were mixed with a one-tenth volume of sample buffer $(0.125 \%$ bromophenol blue, 30\% Ficoll-400, $500 \mathrm{mM}$ EDTA in 10x electrophoresis buffer). The samples were loaded in the wells and electrophoresed for 2 $\mathrm{h}$ at $30 \mathrm{~mA}$. The gels were stained with ethidium bromide $(0.5 \mathrm{ug} / \mathrm{ml})$, viewed by illumination under UV light and photographed.

\subsubsection{Nuclease S1 treatment}

Nitric oxide induced modification was characterized by nuclease S1 treatment[22] followed by agarose gel electrophoresis[23]. One microgram each of native and modified chromatin in acetate buffer $(30 \mathrm{mM}$ each of sodium acetate and zinc chloride, $\mathrm{pH}$ 5.0) were treated with nucleaseS1(20 units/ ug DNA) for $30 \mathrm{~min}$ at $37^{\circ} \mathrm{C}$. The reaction was stopped by adding one tenth volume of $200 \mathrm{mM}$ EDTA,pH 8.0. The digested and control samples were subjected to agarose gel electrophoresis.

\subsubsection{Fluorescence emission spectroscopy}

Fluorescence emission spectroscopy of native and NO-chromatin samples was done using Fluorimeter (Hitachi, Japan). Two different excitation wavelengths were chosen a) $280 \mathrm{~nm}$ and b) $260 \mathrm{~nm}$. At excitation wavelength, $260 \mathrm{~nm}$, fluorescence emission spectroscopy of native and modified samples were recorded using ethidium bromide. While ethidium bromide alone in sample buffer served as control and was used to set the basal line.

\subsubsection{Immunization schedule}

The immunization of random bred, female, New Zealand white rabbits was performed as described previously [24]. Briefly, rabbits $(n=4$; two each of native and NO-chromatin antigens)were immunized subcutaneously at multiple sites with $50 \mathrm{ug}$ of antigen emulsified with an equal volume of complete Freund's adjuvant. The animals were boosted intramuscularly in Freund's incomplete adjuvant at weekly intervals for 5 weeks with the same amount of antigen. Test bleeds were performed 7 days post boost which gave appropriate titre of the antibody. The animals were bled and the serum separated from the blood (preimmune and immune) was decomplemented by heating at $56^{\circ} \mathrm{C}$ $56^{\circ} \mathrm{C}$ for $30 \mathrm{~min}$.

\subsubsection{Purification of antibodies}

Immunoglobulin $\mathrm{G}$ was isolated from immune sera on a Protein A-Sepharose 4B affinity column [25]. The homogeneity of isolated $\mathrm{IgG}$ was checked by performing 7.5\% SDS-polyacrylamide gel electrophoresis.

\subsubsection{ELISA}

An enzyme linked immunosorbent assay (ELISA) was performed on flat bottom 96 well polystyrene immunoplates [26]. Briefly, the plates were coated with $100 \mathrm{ul}$ of respective antigen $(2.5$ $\mathrm{ug} / \mathrm{ml}$ ) for $2 \mathrm{~h}$ at room temperature and over night at $4^{\circ} \mathrm{C}$. After washing three times with TBS-T (20mM Tris, $2.68 \mathrm{mM} \mathrm{KCl}, 150 \mathrm{mM} \mathrm{NaCl}, \mathrm{pH}$ 7.4 containing $0.05 \%$ Tween 20), unoccupied sites were blocked with $1.5 \%$ bovine serum albumin in TBS ( $10 \mathrm{mM}$ Tris, $150 \mathrm{mM} \mathrm{NaCl}, \mathrm{pH}$ 7.4) for 4-6 $\mathrm{h}$ at room temperature. The test serum serially diluted in TBS-T (100ul/well) was adsorbed for $2 \mathrm{~h}$ at room temperature and overnight at $4^{\circ} \mathrm{C}$. Bound antibodies were assayed with anti-human IgG alkaline phosphatase conjugate using p-nitrophenyl phosphate as substrate. The absorbance of each well was monitored at $410 \mathrm{~nm}$ on an automatic microplate reader. Equal number of wells devoid of antigen coating served as controls and the plate was thereafter processed similarly.

\subsubsection{Competition ELISA}

Antibody specificity was ascertained by competition binding assay [27]. Varying concentrations of inhibitors $(0-20 \mathrm{ug} / \mathrm{ml})$ were allowed to interact with a constant amount of antibody (1:100 diluted serum) for $2 \mathrm{~h}$ at room temperature and overnight at $4{ }^{\circ} \mathrm{C}$. The mixture was added to antigen coated plates and the bound (c) 2010 by NWPII. All rights reserved. 
antibody was detected as in the direct binding ELISA.

\subsubsection{Band shift assay}

Band shift assay was performed for the visual detection of antigen antibody binding and immune complex formation [28]. Electrophoresis was performed on $1 \%$ Agarose gel in $40 \mathrm{mM}$ Trisacetate buffer (TAE), $\mathrm{pH}$ 8.0. A constant amount of antigen (2.0 ug) was incubated with increasing concentration $(0-80 \mathrm{ug})$ of affinity purified $\mathrm{IgG}$ for $2 \mathrm{~h}$ at room temperature and overnight at $4{ }^{\circ} \mathrm{C}$ before loading onto the gel. The gel was run at 30 $\mathrm{mA}$ for $2 \mathrm{~h}$, stained with ethidium bromide and visualized under UV light.

\section{Results}

\subsection{Characterization of NO-chromatin}

Freshly isolated chromatin was modified by nitric oxide exposure and the induced changes in NO-chromatin were analyzed by UV absorption spectroscopy. The absorption spectra of NOchromatin showed loss of peak sharpness and hyperchromicity $(51 \%)$ at $260 \mathrm{~nm}$ relative to native chromatin. The modifications incurred on chromatin were also analyzed by UV-difference spectroscopy. The spectral curve exhibited increased absorbance at $240 \mathrm{~nm}$ (data not given).

Agarose gel electrophoresis of native and NO-chromatin was performed on $1 \%$ gel. Single homogenous bands were observed, though there was more stretching seen in case of modified chromatin as compared to its native form (Fig. 1). The generation of single strand breaks in NOchromatin was demonstrated by nucleaseS1 digestibility followed by agarose gel electrophoresis. On digestion, the data (Fig. 2) showed substantial decrease in intensity in case of NO modified sample. However, the intensity loss in case of unmodified chromatin was substantially less as compared to its modified sample.

Fluorescence emission spectra of native and NO-chromatin was taken at two different excitation wavelength, $260 \mathrm{~nm}$ and $280 \mathrm{~nm}$.At 260 $\mathrm{nm}$, using ethidium bromide in the samples, there was marked decrease in the fluorescence intensity of NO-chromatin as compared to native chromatin (Fig. 3a), indicating generation of DNA strand breaks and alterations in the structure of chromatin due to the modification by nitric oxide. However, at wavelength $280 \mathrm{~nm}$, there was marked increase in fluorescence intensity of NOchromatin as compared to native chromatin(Fig. 3b). This may be due to the exposure of chromophoric groups and/or unfolding of proteins in chromatin leading to overall structural alterations occurring due to radical modification.

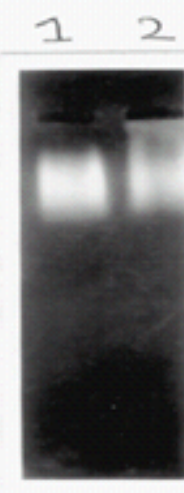

Figure 1. Agarose gel electrophoresis of native chromatin (lane 1) and NO-chromatin (lane2).Electrophoresis was carried out on $1 \%$ agarose gel for $1 \mathrm{hr}$ at $30 \mathrm{~mA}$.

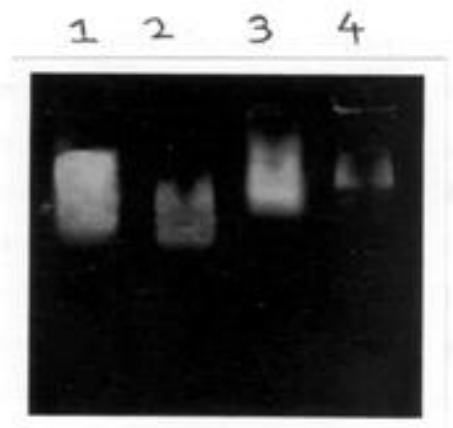

Figure 2. Nuclease S1digestibility of native and NOchromatin. Lane1 contained native chromatin, while lane 2 contained native chromatin treated with nuclease S1.Lane3 contained NO-chromatin; while lane4 contained NO-chromatin treated with nucleaseS 1 for 30 min.Electrophoresis was carried out on $1 \%$ agarose gel for $2 \mathrm{hr}$ at $30 \mathrm{~mA}$.

\subsection{Antigenicity of NO- chromatin}

Native chromatin was found to be immunogenic in rabbits with a titre of at least 1:1600. While NO-chromatin induced a high titre

(C) 2010 by NWPII. All rights reserved. 
antibodies of $>1: 12800$. Protein A-Sepharose isolated (purified) IgGs exhibited strong binding to the respective immunogen (Fig. 4 ). Preimmune IgGs as negative control showed negligible binding.

Competetition ELISA was performed using immunogen: DNA, histones, blood proteins, tyrosine polymer and modified form of nucleosomes as inhibitors to ascertain the antigenic binding specificity of induced antibodies.

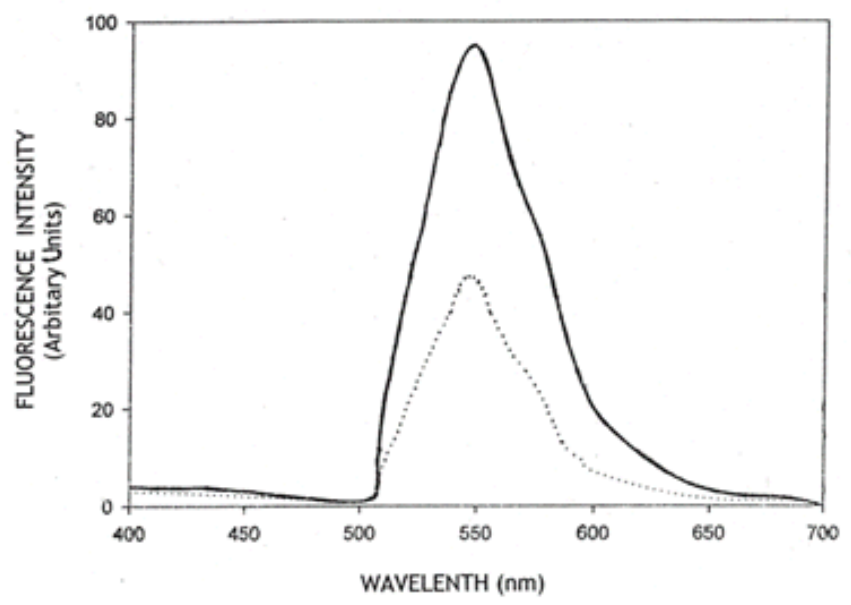

(a)

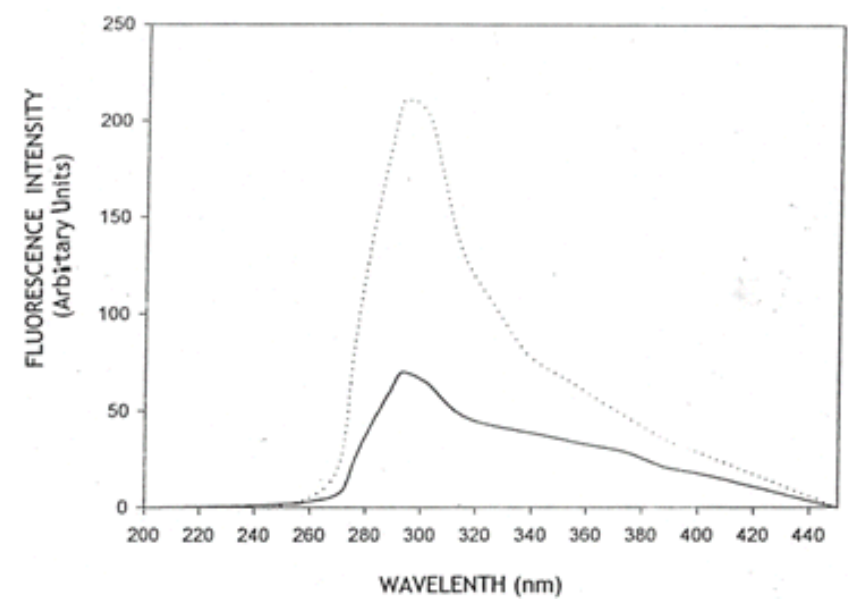

(b)

Figure 3. Fluorescence emission spectrum of native chromatin (-) and NO-chromatin (...).Excitation wavelength was (a) $260 \mathrm{~nm}$ and (b) $280 \mathrm{~nm}$.

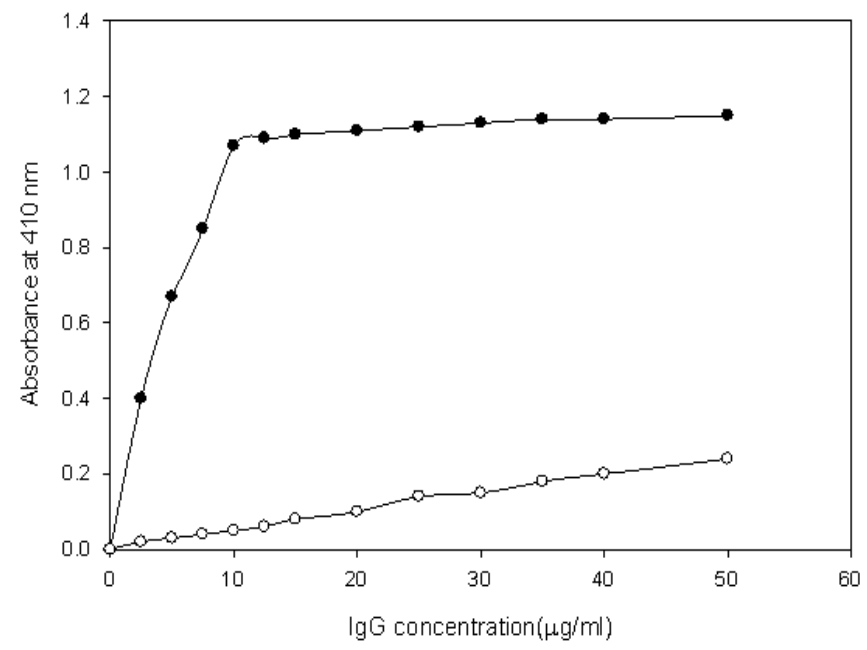

(a)

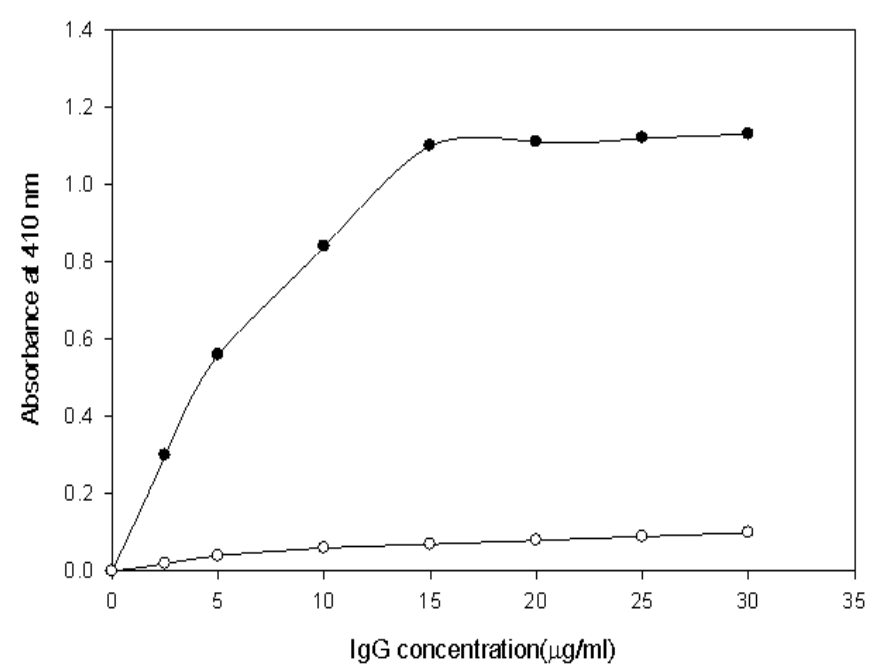

(b)

Figure 4. Direct binding ELISA of affinity purified (a) anti-native chromatin immune $\operatorname{IgG}(\bullet)$ and preimmune IgG (o) to native chromatin. (b) anti-NO-chromatin immune $\operatorname{IgG}(\bullet$ ) and preimmune $\operatorname{IgG}$ (o) to NOchromatin. Microtitre plates were coated with respective immunogen $(2.5 \mu \mathrm{g} / \mathrm{ml})$.

\subsection{Immuno- cross reactivity of anti-native chromatin antibodies}

A maximum of $73 \%$ inhibition of anti- native chromatin antibodies with immunogen as inhibitor was observed.50\% inhibition was achieved with only $13.7 \mu \mathrm{g} / \mathrm{ml}$ of native chromatin. While $33 \%$ inhibition with NO-chromatin as inhibitor for induced antibodies was seen. Native calf thymus 
DNA (nCT DNA) and reactive oxygen species (hydroxyl) ROS-400bp DNA showed only $20 \%$ and $11 \%$ inhibition respectively. On the other hand, native nucleosomes as inhibitor showed maximum inhibition of $57 \%$ with $17.5 \mu \mathrm{g} / \mathrm{ml}$ for $50 \%$ inhibition. While ROS-nucleosome and NOnucleosome showed $22 \%$ and $24 \%$ inhibition respectively. Also $18 \%$ and $12 \%$ maximum inhibition with histone(H2A) and its nitric oxide modified form(NO-HSA) respectively was
achieved.Poly-L-tyrosine, nitric oxide modified poly-L-tyrosine (NO-poly-L-tyrosine) and peroxynitrite modified poly-L-tyrosine $\left(\mathrm{ONOO}^{-}\right.$poly-L-tyrosine) gave only $14 \%, 11 \%$ and $12 \%$ inhibition at $20 \mu \mathrm{g} / \mathrm{ml}$ inhibitor concentration respectively. Human serum albumin (HSA) and ROS-HSA showed $54 \%$ and $37 \%$ inhibition respectively with $18.5 \mu \mathrm{g} / \mathrm{ml} \mathrm{HSA}$ required for $50 \%$ inhibition (Table 1).

Table 1. Antigen binding specificity of anti-native chromatin and NO-chromatin antibodies

\begin{tabular}{l|cc|cc}
\hline \multicolumn{1}{c|}{ Inhibitor } & $\begin{array}{l}\text { Native chromatin } \\
\text { Maximum } \% \text { inhibition } \\
\text { at } 20 \mu \mathrm{g} / \mathrm{ml}\end{array}$ & $\begin{array}{l}\text { Conc. For } \\
50 \% \text { inhibition } \\
(\mu \mathrm{g} / \mathrm{ml})\end{array}$ & $\begin{array}{l}\text { NO- chromatin } \\
\text { Maximum } \% \\
\text { inhibition at } 20 \mu \mathrm{g} / \mathrm{ml}\end{array}$ & $\begin{array}{l}\text { Conc. For } \\
50 \% \text { inhibition } \\
(\mu \mathrm{g} / \mathrm{ml})\end{array}$ \\
\hline Native chromatin & 73 & 13.7 & 58.5 & 17.0 \\
NO-chromatin & 33 & - & 98.4 & 10.16 \\
Native calf thymus DNA & 20 & - & 15 & - \\
ROS-400bp DNA & 11 & - & 19 & - \\
Native nucleosome & 57 & 17.5 & 52 & 19.2 \\
ROS-nucleosome & 22 & - & 59 & 16.9 \\
NO-nucleosome & 24 & - & 68 & 14.7 \\
Histone (H2A) & 18 & - & 29 & - \\
NO-histone(H2A) & 12 & - & 20 & - \\
Poly-L-tyrosine & 14 & - & 38 & - \\
NO-poly-L-tyrosine & 11 & - & 45 & - \\
ONOO- poly-L-tyrosine & 12 & - & 62 & 16.1 \\
Human serum Albumin (HSA) & 54 & 18.5 & 65 & 15.3 \\
ROS-HAS & 37 & - & & \\
\hline
\end{tabular}

\subsection{Immuno- crossreactivity of anti-NO- chromatin antibodies}

The anti-NO-chromatin antibodies exhibited wide range of heterogeneity as demonstrated by inhibition assay using various inhibitors. A maximum of $98.4 \%$ inhibition with immunogen as inhibitor was observed with $50 \%$ inhibition achieved at $10.2 \mu \mathrm{g} / \mathrm{ml}$ of NO-chromatin. The induced antibodies recognized native chromatin and showed $58.5 \%$ maximum inhibition with 17 $\mu \mathrm{g} / \mathrm{ml}$ required for $50 \%$ inhibition of antibody binding. Native calf thymus DNA and ROS400bpDNA showed only $15 \%$ and $19 \%$ inhibition respectively. On the other hand, moderate to high inhibition was seen with native nucleosome, ROS- nucleosome and NO-nucleosome which was 52\%, $59 \%$ and $68 \%$ respectively, while $50 \%$ inhibition was achieved at $19.2 \mu \mathrm{g} / \mathrm{ml}, 16.9 \mu \mathrm{g} / \mathrm{ml}$ and 14.7 $\mu \mathrm{g} / \mathrm{ml}$ respectively. Also, $29 \%$ and $48 \%$ inhibition was achieved with histone (H2A) and NO-H2A as inhibitors respectively. While poly-L-tyrosine, NO-poly-L-tyrosine and $\mathrm{ONOO}^{-}$-poly-L-tyrosine as inhibitors showed 20\%, 38\% and $46 \%$ inhibition respectively. Blood proteins like HSA and ROS-HSA showed maximum inhibition of $62 \%$ and $65 \%$ with anti-NO-chromatin antibodies respectively. $50 \%$ inhibition was achieved at 16.1 $\mu \mathrm{g} / \mathrm{ml}$ and $15.3 \mu \mathrm{g} / \mathrm{ml}$ concentration respectively (Table 1). 
The formation of immune complex of NOchromatin and anti-NO-chromatin antibodies was visualized by band shift assay. As clearly evident with increasing amount of $\mathrm{IgG}$ the formation of high molecular weight immune complex increased, as judged by their fluorescence intensity in the wells, whereas retardation of chromatin bands with decreased intensity of unbound antigen was seen( Fig. 5a). The recognition of native chromatin by anti-NOchromatin IgG was similarly demonstrated by shift in electrophoretic mobility with proportional decrease in intensity of unbound chromatin upon immune complex formation which is consistent with the data in table 1 (Fig. 5b).

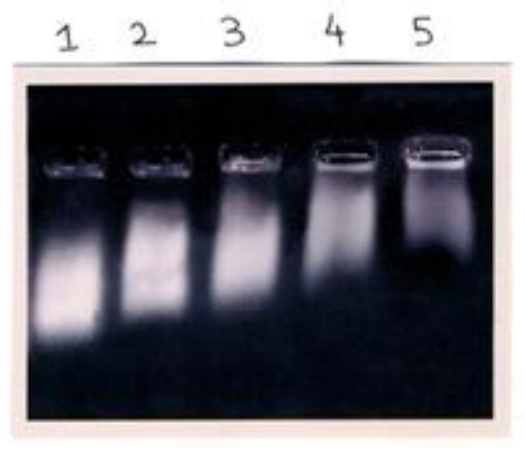

(a)

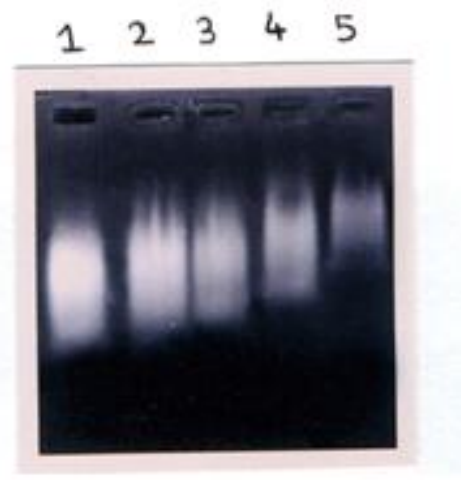

(b)

Figure 5. Band shift assay of anti-NO-chromatin IgG binding to NO-chromatin and native chromatin. (a) NO-chromatin ( $2 \mathrm{ug}$ ) was incubated with buffer (lane1) and 20,30, 50 and $60 \mathrm{ug}$ IgG through lanes 2 to 5 respectively. (b) Native chromatin (2 ug) was incubated with buffer (lane1) and 20, 30, 50 and 60ug IgG through lanes 2 to 5 respectively for $2 \mathrm{hr}$ at $37^{\circ} \mathrm{C}$ Am. J. Biomed. Sci. 2010, 2(2), 98-107; doi: 10.5099/aj100200098 and overnight at $4^{0} \mathrm{C}$. Electrophoresis was carried out on $1 \%$ agarose gel for $2 \mathrm{hr}$ at $30 \mathrm{~mA}$.

\section{Discussion}

Nitric oxide (NO), a multifaceted bioregulatory agent, shows an unusual divergence of action. It is known to play a major role as neurotransmitter and a regulator of blood pressure. Also, nitric oxide is an important mediator of the inflammatory response. Over expression of NOS2 and nitric oxide are parallel with the development of an autoimmune syndrome with variety of inflammatory manifestations like SLE, rheumatoid arthritis and multiple sclerosis [29,30,31]. Nitric oxide is known to cause cell injury via variety of mechanisms including disruption of mitochondrial respiration, enzyme inhibition, lipid peroxidation and genetic mutation. Toxicity is largely mediated through intermediates such as $\mathrm{N}_{2} \mathrm{O}_{3}$ and peroxynitrite, involving nitric oxide with either molecular oxygen or ROS. Though, a high concentration of nitric oxide generated by the induction of NOS is required [32,33,34]. Macrophages use nitric oxide as a cytotoxic agent which may lead to DNA damage. The effects of nitric oxide at the DNA level are complex and involve formation of $\mathrm{N}$-nitrosamines, deamination of purines and pyrimidines or damage induced by peroxynitrite $[5,6,35]$. There is also possibility of intrastrand cross-linking via attack of any diazonium ion of one purine on the free amino group of a second purine in the matching strand [36].

Nitric oxide radical caused substantial damage to chromatin, as evident from the loss of peak and hyperchromicity observed at $260 \mathrm{~nm}$ as compared to its native form. This could be attributed to strand breaks and base modifications in DNA of chromatin. No change was observed in chromatin incubated with either sodium nitrite or sodium dithionite alone.

Formation of single stranded regions in modified chromatin was confirmed by nuclease S1 digestibility of native and modified chromatin. The intensity loss in case of native chromatin can be attributed to some single stranded regions already present in unmodified sample (sheared liver chromatin). However; the intensity loss in

(C) 2010 by NWPII. All rights reserved.

104 
modified sample was more, showing the formation of single stranded regions on exposure to nitric oxide. The data is compatible with earlier reports indicating nitric oxide radical result in strand breaks [22, 37]. Also, fluorescence studies of NOchromatin compared with native chromatin showed prominent changes in spectral studies. It confirmed the alterations in structural organization of chromatin incurred by nitric oxide exposure.

Chromatin itself is immunogenic but in diseases like SLE, it becomes more immunogenic[38,39,40]. This might be due to the exposure of chromatin to various free radicals including nitric oxide radicals altering its structure and rendering it more immunogenic. Both native and modified chromatin was found to be immunogenic in rabbits. But NO-chromatin was found to be highly immunogenic as compared to its unmodified form. Antibodies raised against native and NO-chromatin were further determined for their antigenic binding characteristics with various inhibitors. Besides showing strong recognition for their respective immunogen, antiNO-chromatin antibodies showed cross-reactivity with native chromatin as well. This may be due to the common antigenic determinant to both NOchromatin and native chromatin. Gel retardation data reiterated the preferential recognition of $\mathrm{NO}$ modified chromatin over native chromatin by the anti-NO-chromatin antibodies. However, pure ds DNA or ROS modified DNA fragment (ROS-400 bp) did not appreciably recognized the induced antibodies .The data suggests that DNA alone may not be responsible for antibody generation rather quaternary DNA-protein complex is the neoepitope recognized by the antibodies against native and modified chromatin. Also, native nucleosomes, ROS-nucleosome and NOnucleosomes showed moderate to high percent cross-reactivity for antibodies generated against native and NO-chromatin.

On the other hand,histone(H2A), a core binding protein in nucleosomes, showed negligible inhibition with anti-native chromatin $\mathrm{IgG}$ as compared with anti NO- chromatin IgG(moderate inhibition). It is reported that antigenicity of histones bound to chromatin is markedly diminished as compared to histones free in solution[41]. However, histones on modification with nitric oxide generate similar epitopes as recognized by anti-NO-chromatin antibodies.3Nitrotyrosine is a biological marker of oxidative damage by nitric oxide[42,43]. Therefore, in case of anti-NO-chromatin IgG, native tyrosine polymer (poly-L-tyrosine) used as inhibitor, showed negligible inhibition compared to tyrosine polymer modified with nitric oxide and one of its radical, peroxynitrite. Thus, tyrosine on initiation generates epitopes for antibody recognition similar to epitopes generated by NO-chromatin. Similarly human blood protein like human serum albumin (HSA) and its ROS modified forms show moderate to high recognition for antibodies indicating similar epitope sharing or crossreactivity. Analysis of the data indicates that antiNO-chromatin IgG is immunogenic specific and the varying degree of cross-reactivity is due to the sharing of common antigenic determinants.

Several studies have reinforced the concept that SLE is an anti-chromatin disease i.e. the auto immune response is against the chromatin with development of antibodies directed to various epitopes on chromatin including but not limited to DNA alone[40,41,44]. It has been proposed that a defect in the catabolism of chromatin may render it immunogenic. The change in chromatin's antigenicity by environmental factors and genetic background may be the common pathway to SLE pathogenesis [13].Our preliminary studies using protein A-Sepharose 4B purified SLE autoantibodies from SLE sera showed higher inhibition by NO-chromatin in comparison to native chromatin and native calf thymus DNA, when the immobilized antigen was native calf thymus DNA. The present study clearly shows the perturbations in chromatin by nitric oxide radical rendering it highly immunogenic and the neo- epitopes might play a role in the induction of circulating autoantibodies in SLE.

\section{Bibliography}

1. Lowenstein, C.J.; Dinerman, J.L.; Synder, S.H. Nitric oxide: a physiological messenger. Ann Intern Med, 1994, 120,227-237.

2. Keefer, L.K.; Wink, D.A.; Kasparazak, K.S.DNA deaminating ability and genotoxicity 
of nitric oxide and its progenitors. Science, 1991, 254,1001-1003.

3. Drapier, J.C.; Hirling, H.; Wietzerbin, J.; Kaldy, H.; Kuehn, L.G. Biosynthesis of nitric oxide activates iron regulatory factor in macrophages. EMBO J,1993, 12, 3643-3649.

4. Lepoivre, M.; Fieschl, F.; Coves, J.; Thelander, L.; Fontecave, M. Inactivation of ribonucleotide reductase by nitric oxide. Biochem. Biophys. Res. Commun,1991, 179,442-448.

5. Delaney, C.J.; Eizirik, D.J. Intracellular target for nitric oxide toxicity to pancreatic betacells.Braz. J. Med. Biol. Res,1996, 29,569579.

6. Luperchio, S.; Tamir, S.; Tannenbaum, S.R. NO-induced oxidative stress and glutathione metabolism in rodent and human cells. Free Radic. Biol. Med,1996, 21,513-519.

7. Tan, E.M.Autoantibody to nuclear antigens (ANA): their immunology and medicine.Adv. Immunol, 1982, 33,167-240.

8. Mohan, C.; Adams, S.; Stanik, V.; Datta, S.K. Nucleosome: A major immunogen for pathogenic antibody-inducing $\mathrm{T}$ cells of Lupus. J Exp Med,1993, 177,1367-1381.

9. Burlingame, R.W.; Rubin, R.L.; Balderas, R.S.; Theofilopoulos, A.N. Genesis and evolution of antichromatin autoantibodies in murine lupus implicates T-dependent immunization with self antigen. J Clin Invest,1993, 91,687-1696.

10. Burlingame, R.W.; Boey, M.L.; Starkebaum, G.; Rubin, R.L. Central role of chromatin in autoimmune response to histones and DNA in systemic lupus erythematosus. J Clin Investig, 1994, 94,184-192.

11. Amoura, Z.; Chabre, H.; Koutouzov, S.; Lotton, C.; Cabrespines, A.; Bach, J.F., Jacob, L. Nucleosome-restricted antibodies are detected before anti-DNA and/or anti-histone antibodies in serum of MRL-Mp Ipr/Ipr and $+/+$ mice and are present in kidney elutes of lupus mice with proteinuria. $\mathrm{J}$ Clin Investig, 1994, 37,1684-1688.

12. Chabre, H.; Amoura, Z.; Piette, J.C.; Godeau, P.; Bach, J.F., Koutouzov, S. Presence of nucleosome-restricted antibodies in patients with systemic lupus erythematosus. Arthritis Rheum,1995, 38,1485-1491.

13. Tax, W.J., Kramers, C.; vanBruggen, M.C.; Berden, J.H. Apoptosis, nucleosomes and nephritis in systemic lupus erythematosus. Kidney Int, 1995, 48, 666-673.

14. Mansoor, F., Ali, A., Ali, R.Binding of circulating SLE autoantibodies to oxygen free radical damaged chromatin. Autoimmunity,2005, 38,431-438.

15. White, K.A.; Marletta, M.A. Nitric oxide synthase is a cytochrome P-540 type hemoprotein.Biochemistry, 1992, 31,66276631.

16. McMillan, K.; Bredt, D.S.; Hirsch, D.J.; Synder, S.H.; Clark, J.E.; Masters, B.S. Cloned,expressed rat cerebellar nitric oxide synthase contains stoichiometric amounts of heme, which binds carbon monoxide.Proc.Natl.Acad.Sci. USA, 1992, 89,1141-1145.

17. Belmont, H.M.; Levartovsky, D.; Goel, A. Increased nitric oxide production accompanied by the upregulation of inducible nitric oxide synthase in vascular endothelium from patients with systemic lupus erythematosus. Arthritis Rheum,1997, 40,1810-1816.

18. Wanchu, A.; Khuller, M.; Deodhar, S.D. Nitric oxide synthesis is increased in patients with systemic lupus erythematosus. Rheumatol Int,1998, 18,41-43.

19. Bonner, J.; Chalkley, G.R.; Dahmus, M.; Fambrough, D.; Fujimura, F.; Huang, R.C.; Huberman, J.; Jensen, R.; Marushige, K.; Ohlenbusch, H.; Olivera, B.; Widholm, J. Isolation and characterization of chromosomal nucleoproteins. Methods Enzymol,1968, XIIB, 3-8.

20. Dixit, K.; Ali, R. Antigen binding characteristics of antibodies induced against nitric oxide modified plasmid DNA. Biochim Biophys, 2001, 1528,1-8.

21. Sugiuria, Y.; Matsumoto, T. Nucleotide selective cleavage of duplex DNA by nitric oxide. Biochem Biophys Res Commun,1994, 211,748-753.

22. Matsuo, N.; Ross, P.M. Measurement of interstrand crosslink frequency and distance between interruptions in DNA exposed to 4, 
5', 8-trimethylpsoralen and near-ultraviolet light. Biochemistry, 1987, 26,2001-2009.

23. Islam, N.; Ali, R. Formation of thymine-lysine and cytosine-lysine adducts in DNA-lysine photoconjugate.J. Photochem. Photobiol. Biol,1995, 27,109-115.

24. Hasan, R.; Ali, A.; Ali, R. Antibodies against DNA-psoralen crosslink recognize unique conformation. Biochim Biophys Acta,1991, 1073,509-513.

25. Goding, J.W. The chromic chloride method of coupling antigens to erythrocytes: definition of some important parameters. J Immunol Methods, 1976, 10,61-66.

26. Ali, R., Alam, K. Evaluation of antibodies against free radical modified DNA by ELISA. In: Armstrong D, editor. Oxidative stress biomarkers and antioxidants protocols. New Jersey: Humana Press, 2002, 171-181.

27. Ali, A.; Hasan, R.; Ali, R. Antigen binding diversity of affinity purified autoantibodies against DNA Biochem Int,1991, 23,111-118.

28. Alam, K.; Ali, R. Human autoantibody binding to multiple conformations of DNA Biochem Int, 1992, 26,597-605.

29. Cook, H.T.; Cattell, V. Role of nitric oxide in immune-mediated diseases. Clin Sci (Lond), 1996, 91,375-384.

30. Parkinson, J.F.; Mitrovic, B.; Merrill, J.E. The role of nitric oxide in multiple sclerosis. $\mathrm{J} \mathrm{Mol}$ Med,1997, 75,174-186.

31. Kuhn, A.; Fehsel, K.; Lehman, P.; Krulman, J.; Ruzicka, T.; Kolb-Bachofen, V. Aberrant timing in epidermal expression of inducible nitric oxide synthase after UV irradiation in cutaneous lupus erythematosus. J Invest Dermatol,1998, 111,149-153.

32. Gordge, M.P. How cytotoxic is nitric oxide? Exp Nephrol,1998, 6,6-12.

33. Wink, D.A.; Feelisch, M.; Fukoto, J.; Chistodoulou, D. The cytotoxicity of nitroxyl: possible implications for the pathophysiological role of NO. Arch Biochem Biophys, 1998 351,66-74.

34. Wink, D.A.; Vodovotz, Y.; Laval, J.; Laval, F.; Dewhirst, M.V.; Mitchell, J.B. The multifaceted roles of nitric oxide in cancer. Carcinogenesis, 1998, 19,711-721.

35. Lin, J.K.; Wang, J.M.; Lin-Shiau, S.Y. Relaxation of rat thoracic aorta by N-nitroso compounds and nitroprusside and their modifications of nucleic acid bases through release of nitric oxide. Biochem Pharmacol,1993, 45,819-825.

36. Kirchner, J.J.; Hopkins, P.B. Sequence preferences of DNA interstrand crosslinking agents: quantitation of interstrand crosslink locations in DNA duplex fragments containing multiple cross linkable sites. Nucleic Acids Res, 1991, 19,1885-1891.

37. Kolb, H.; Fehsel, K.; Jalowy, A.; Qi, S.; Burkart, V.; Hartmann, B. Islet cell DNA is a target of inflammatory attack by nitric oxide. Diabetes, 1993, 42,496-500.

38. Hardin, J.A.. The lupus autoantigens and the pathogenesis of systemic lupus erythematosus. Arthritis Rheum,1986, 29,457-460.

39. Chabre, H.; Amoura, Z.; Piette, J.C. Presence of nucleosome-restricted antibodies in patients with systemic lupus erythematosus. Arthritis Rheum,1995, 38,1485-1491.

40. Burlingame, R.W.; Boey, M.L.; Starkebaum, G.; Rubin, R.L. The central role of chromatin in autoimmune responses to histones and DNA in systemic lupus erythematosus. J Clin Invest,1994, 94,184-192.

41. Goldblatt, D.; Bustin, M. Antigenicity of histones in various chromatins. Biochim Biophys Acta, 1980, 606,304-315.

42. Ishiropoulos, H.; Zhu, L.; Beckman, J.S. Peroxynitrite formation from macrophagederived nitric oxide. Arch Biochem Biophys, 1992, 298,446-451.

43. Beckman, J.S.; Beckman, T.W.; Chen, J.; Marshall, P.A.; Freeman, B.A. Apparent hydroxyl radical production by peroxynitrite: implications for endothelial injury from nitric oxide and superoxide. Proc Natl Acad Sci U S A, 1990, 87,1620-1624.

44. Tax, W.J.; Kramers, C.; Berdin, J.H.; van Bruggen, M.C. Apoptosis, nucleosomes, and nephritis in systemic lupus erythematosus. Kidney Int,1995, 48,666-673. 